\title{
Development of 1 MJ Conduction-Cooled LTS Pulse Coil for UPS-SMES
}

\author{
Toshiyuki Mito, Akifumi Kawagoe, Hirotaka Chikaraishi, Ryuji Maekawa, Tsutomu Hemmi, Kagao Okumura, \\ Ryo Abe, Tomosumi Baba, Hideki Ogawa, Mitsuhiro Yokota, Yoshitaka Morita, Kenji Yamauchi, \\ Masataka Iwakuma, Atsuko Kuge, Akira Nakamura, and Fumio Sumiyoshi
}

\begin{abstract}
A 1 MW, 1 s UPS-SMES is being developed for a protection from a momentary voltage drop and an instant power failure. As a key technology of the UPS-SMES, we developed a prototype LTS pulse coil with a stored energy of $100 \mathrm{~kJ}$ and conducted cooling and excitation tests in 2005 . The operation test of the prototype UPS-SMES using this $100 \mathrm{~kJ}$ coil with power converters have been performed in 2006. A $1 \mathrm{MJ}$ coil was designed before the fabrication of the $100 \mathrm{~kJ}$ prototype coil. The superconductor, the electric insulation technique, the winding method, and the cooling structure used for the $100 \mathrm{~kJ}$ coil were based upon the $1 \mathrm{MJ}$ coil design. The successful performance test results of the prototype $100 \mathrm{~kJ}$ coil validated the design concept and fabrication technique of the $1 \mathrm{MJ}$ coil. According to the achievement of the prototype $100 \mathrm{~kJ}$ UPS-SMES, the $1 \mathrm{MJ}$ conduction-cooled LTS pulse coil has been fabricated successfully. The successful experimental results of the $100 \mathrm{~kJ}$ prototype coil with power converters and the fabrication procedure of the $1 \mathrm{MJ}$ full size coil are described.
\end{abstract}

Index Terms-Conduction cooled, momentary voltage drop, superconducting pulse coil, UPS-SMES.

\section{INTRODUCTION}

W E have been developing a 1 MW, $1 \mathrm{~s}$ UPS-SMES for a protection from momentary voltage drop and an instant power failure as a five-year project from 2002 to 2006 fiscal years in a research promotion program of NEDO. A conduction-cooled Low Temperature Superconducting (LTS) pulse coil has been developed as a key technology for this UPS-SMES. A conduction-cooled LTS pulse coil has excellent characteristics, which are adequate for a short-time UPS. The LTS coil has a better cost performance over the HTS coil at present and the conduction cooling has higher reliability and easier operation than the conventional cooling schemes such as pool boiling with liquid helium [1], [2] or forced flow of supercritical helium. We developed a $100 \mathrm{~kJ}$ prototype UPS-SMES in order to evaluate the conceptual design and the manufacturing procedure. According to the successful experimental results of the $100 \mathrm{~kJ}$ coil

Manuscript received August 29, 2006. This work was supported by NIFS (NIFS05ULAA102), the Grant of NEDO, and the Grant-in-Aid for Scientific Research (\#16206028).

T. Mito, H. Chikaraishi, R. Maekawa, T. Hemmi, T. Baba, H. Ogawa, M. Yokota, Y. Morita, and K. Yamauchi are with the National Institute for Fusion Science, Gifu 509-5292, Japan (e-mail: mito@LHD.nifs.ac.jp).

A. Kawagoe and F. Sumiyoshi are with the Kagoshima University, Kagoshima, 890-0065, Japan.

K. Okumura and A. Kuge are with the Technova Inc., Tokyo 100-0011, Japan.

R. Abe and A. Nakamura are with Shibuya Kogyo Co. Ltd., Kanazawa, 9208681, Japan.

M. Iwakuma is with Kyushu University, Fukuoka 812-8581, Japan.

Digital Object Identifier 10.1109/TASC.2007.898081 excitation tests and the energy extraction tests with power converters, we have proceeded to develop 1 MJ LTS pulse coils for 1 MW, 1 s UPS-SMES.

\section{PROtotyPe 100 kJ UPS-SMES DEVELoPMENT}

\section{A. Cooling and Excitation Test Summary of $100 \mathrm{~kJ}$ Coil}

The $100 \mathrm{~kJ}$ coil was connected with two GM cryocoolers which had the total cooling capacity of $3 \mathrm{~W}$ at $4 \mathrm{~K}$ and $120 \mathrm{~W}$ at $50 \mathrm{~K}$, respectively. The coil was placed in a test cryostat which was evacuated for the performance test. During the cool down, the spatial temperature distributions within the coil were negligible because of the high thermal conductivity in the windings. The coil temperatures reached below $4 \mathrm{~K}$ within five days.

By applying the rated current of $1000 \mathrm{~A}$ for an hour, the coil maintained a stable operating condition with a rated stored energy of $100 \mathrm{~kJ}$. Furthermore, the coil had been excited up to 1420 A with a stored energy of $200 \mathrm{~kJ}$ repeatedly and was stably operated for an hour. In a high speed discharging test, the coil current was reduced rapidly from 1420 A to 0 A with a time constant of $1.3 \mathrm{~s}$. The temperature increase within the coil was less than $0.8 \mathrm{~K}$ so that the heat generated by the AC loss of $278 \mathrm{~J}$ was well distributed within the coil windings. These test results exceeded the expected performance of the coil [3]. The prototype $100 \mathrm{~kJ}$ coil demonstrated its high potentiality thanks to the good thermal design.

\section{B. Performance Tests of Prototype 100 kJ UPS-SMES System}

A detailed 2D-FEM analysis of the thermal properties of the $100 \mathrm{~kJ}$ coil had been carried out [4]. Consequently, the high heat transfer properties of the coil were well justified. The stability margins of the $100 \mathrm{~kJ}$ coil were evaluated, which has about three times larger than the expected value. Therefore the $100 \mathrm{~kJ}$ coil can be operated at the energy extraction mode of $150 \mathrm{~kW}$ which is three times larger than the rated output power of $50 \mathrm{~kW}$.

To demonstrate the high performance of the $100 \mathrm{~kJ}$ coil, the coil energy extraction tests with power converters have been conducted. The test circuit is shown in Fig. 1 . In the figures, $\mathrm{v}_{\mathrm{dc}}$ is dc link voltage, $i_{\mathrm{dc}}$ is current flowing the $\mathrm{dc}$ link, $\mathrm{p}_{\mathrm{dc}}$ is power at the dc link, $\mathrm{v}_{\mathrm{c}}$ is coil terminal voltage, $\mathrm{i}_{\mathrm{c}}$ is current flowing the coil and $p_{c}$ is power from the coil, respectively. The excitation test results demonstrated the sufficient operational margin of the $100 \mathrm{~kJ}$ coil and the power converters were designed with a rating of $150 \mathrm{~kW}$ for a short time operation. The available power is limited with $\mathrm{i}_{\mathrm{c}}$ and $\mathrm{v}_{\mathrm{dc}}$. In this system, $\mathrm{v}_{\mathrm{dc}}$ is $300 \mathrm{~V}$ and $150 \mathrm{~kW}$ outputs is possible, while $i_{c}$ is larger than 500 A. Fig. 2 and Fig. 3 show the successful test results of the prototype $100 \mathrm{~kJ}$ 


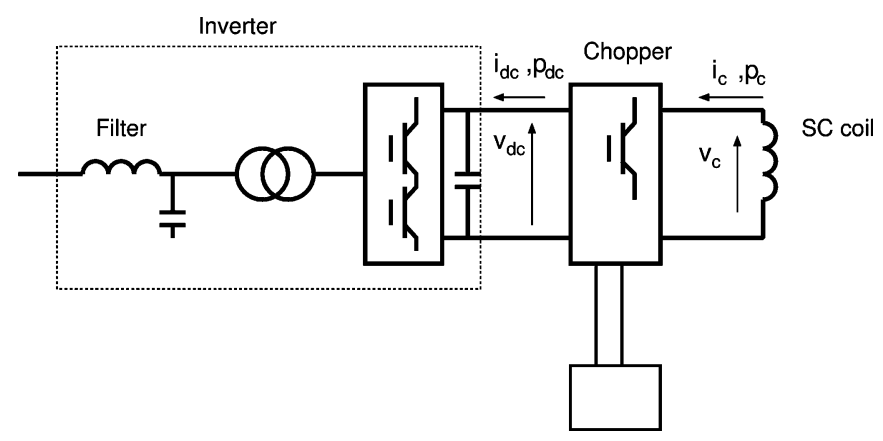

Fig. 1. Test circuit diagram for the prototype $100 \mathrm{~kJ}$ UPS-SMES system.

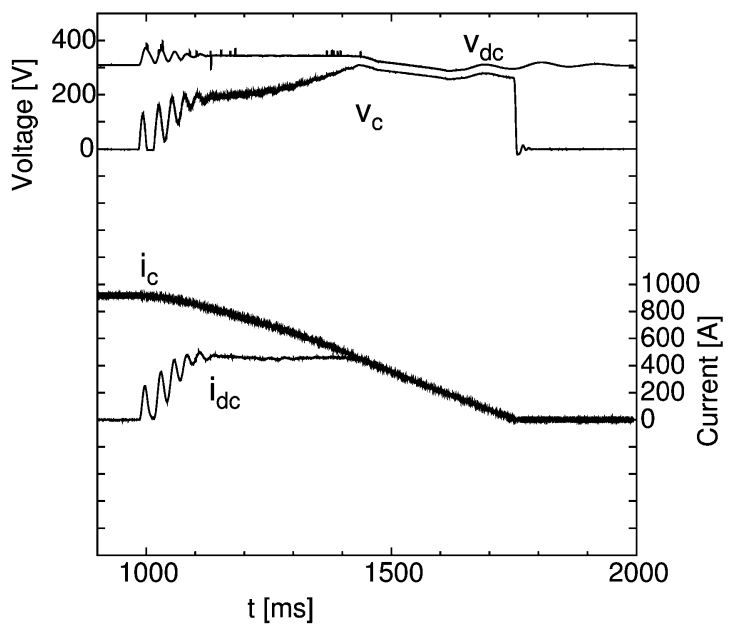

Fig. 2. Coil voltage, current and power for $150 \mathrm{~kW}$ discharge operation.

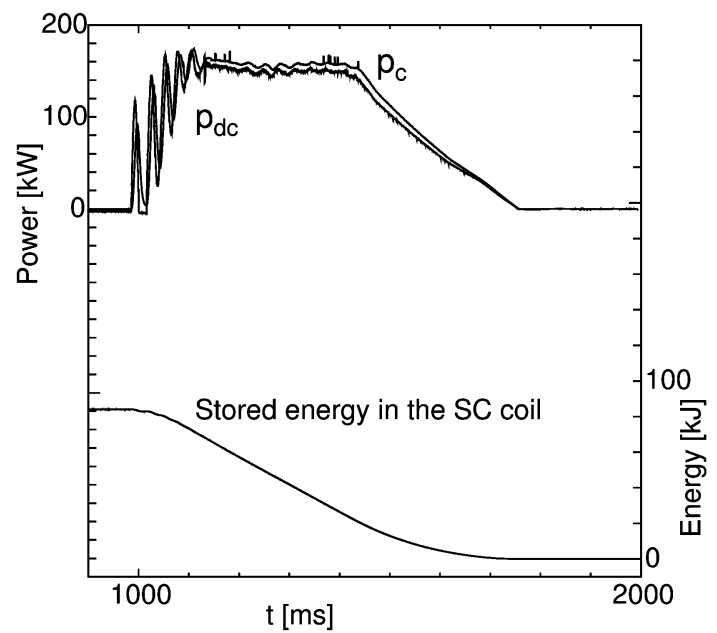

Fig. 3. DC power flows in the dc link of the converters and stored energy in the coil.

UPS-SMES. The $\mathrm{v}_{\mathrm{dc}}, \mathrm{v}_{\mathrm{c}}, \mathrm{i}_{\mathrm{c}}$ and $\mathrm{i}_{\mathrm{dc}}$ are shown in Fig. 2. The discharge started at $\mathrm{t}=1000 \mathrm{~ms}$ and stopped at $\mathrm{t}=1720 \mathrm{~ms}$. In order to check the operation of the chopper, the discharge operation was continued until $i_{c}$ became 0 A. Fig. 3 shows the stored energy in the coil and $\mathrm{p}_{\mathrm{c}}$. The $\mathrm{p}_{\mathrm{dc}}$ had been kept constant at $150 \mathrm{~kW}$ at $\mathrm{t}=1000-1440 \mathrm{~ms}$.

The $100 \mathrm{~kJ}$ UPS-SMES successfully demonstrated its high performance, which was three times larger $(150 \mathrm{~kW})$ than the rated output power of $50 \mathrm{~kW}$, even though the time duration was limited to $0.44 \mathrm{~s}$. After this discharge operation, the temperature

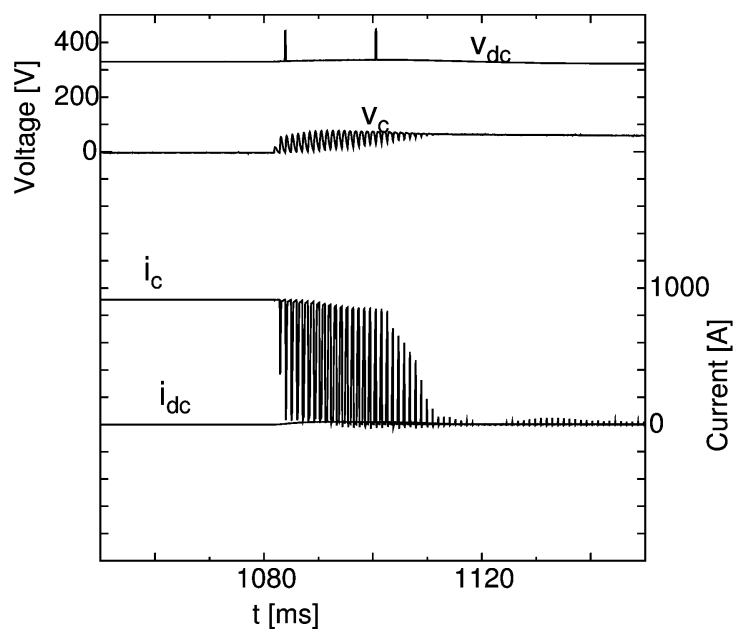

Fig. 4. Coil voltage and current when the electrical breakdown was occurred.

of the coil increased about $1 \mathrm{~K}$, which was smaller than the designed value.

\section{Electrical Breakdown in Test Cryostat}

At the end of these operation tests, an electrical breakdown in the test cryostat occurred, as shown in Fig. 4 . At $\mathrm{t}=1080 \mathrm{~ms}$, the high voltage was applied at the start of the discharge, the $\mathrm{i}_{\mathrm{c}}$ suddenly dropped to $0 \mathrm{~A}$ and recovered to $1 \mathrm{kA}$. At $\mathrm{t}=$ $1080-1110 \mathrm{~ms}$, the $\mathrm{i}_{\mathrm{c}}$ oscillated between $1 \mathrm{kA}$ and $0 \mathrm{~A}$ more than 20 times. This current indicated that many small breakdowns and recovers occurred in the cryostat. After the warm up of the system, we opened the cryostat and checked discharge traces. Large traces were found between the cryocoolers, the HTS current leads and the inner flange. Also many traces were found in the diagnostic wires such as for thermal sensors and voltage taps, and some of them were melted. When we designed the test cryostat for the prototype $100 \mathrm{~kJ}$ UPS-SMES, the average terminal voltage of the coil was estimated to be around $70 \mathrm{~V}$ from the specification of the system. In the test operation, however, the maximum coil terminal voltage became around $300 \mathrm{~V}$ because of the insufficient matching of the converter and the coil [5], and it might have exceeded the dielectric voltage of the insulation of the sensor wires Also, some terminals of the wires had been shorted accidentally at the outside of the cryostat.

With these results we infer as follows. With discharge operations, a high operation voltage which exceeded the dielectric strength of the wires was applied. At first, the resistance of electric insulators of wires was rapidly decreased. Therefore the large current flows in the wire and it was melted. When the wire melted, the flowing current stopped and insulation was recovered temporarily, but the terminal voltage ramped up again and another wire suffered from an electrical breakdown. With these small discharges, some amount of gas was released in the cryostat and the vacuum pressure in the cryostat increased. Finally, the applied voltage might have exceeded the withstand voltage among the HTS current leads, the cryocoolers and the cryostat, and a large discharge occurred in the cryostat. However, there was no damage in the coil itself after these electrical breakdowns. 


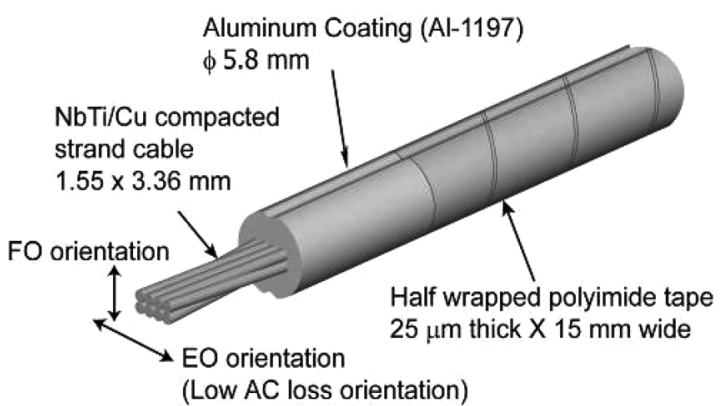

Fig. 5. Superconducting conductor for the LTS pulse coil.

TABLE I

SPECIFICATIONS OF THE SC CONDUCTOR

\begin{tabular}{ll}
\hline \hline Conductor type & $\begin{array}{l}\text { Aluminum coated NbTi/Cu } \\
\text { compacted strand cable }\end{array}$ \\
Conductor diameter & $5.8 \mathrm{~mm}$ \\
Critical current & $3740 \mathrm{~A} @ 5 \mathrm{~T}, 4.2 \mathrm{~K}$ \\
Insulation & $25 \mu \mathrm{m}$ thick $\times 15 \mathrm{~mm}$ wide \\
Outer diameter with insulation & Half wrap winding of Polyimide tape \\
Tensile strength & $5.9 \mathrm{~mm}$ \\
$0.2 \%$ Yield strength & $96 \mathrm{MPa}$ \\
Coupling time constant of AC & $89 \mathrm{Mpa}$ \\
loss: $\mathrm{A}^{*} \tau$ & $10 \mathrm{msec}$ for edge-on (EO) orientation \\
Compacted strand cable & \\
$\quad$ Number of strands & 8 \\
Strand diameter & $0.823 \mathrm{~mm}$ \\
Dimension & $1.55 \times 3.36 \mathrm{~mm}$ \\
Aluminum coating & \\
$\quad$ Material & $\mathrm{Al}-1197$ \\
RRR & 9.85 \\
\hline \hline
\end{tabular}

\section{DeVelopMent OF 1 MJ CoIL}

\section{A. Design Similarities Between 1 MJ Coil and 100 kJ Coil}

A $1 \mathrm{MJ}$ coil was designed before the fabrication of the $100 \mathrm{~kJ}$ prototype coil. Therefore, the superconductor, the electric insulation technique, the winding method, and the cooling structure used for the $100 \mathrm{~kJ}$ coil were based upon the $1 \mathrm{MJ}$ coil design. Fig. 5 shows the conductor configuration and its parameters are listed in Table I. The parameters of the $1 \mathrm{MJ}$ full size coil are listed in Table II as compared with the $100 \mathrm{~kJ}$ coil. In the $1 \mathrm{MJ}$ UPS-SMES, the terminal voltage becomes $707 \mathrm{~V}$, and we designed to use high voltage insulation wires for the diagnostic sensors and enough insulators surround the HTS current leads and the cryocoolers to avoid electrical breakdown such as the one observed during the test of the $100 \mathrm{~kJ}$ prototype coil. The insulation structures of the conductor and the coil windings are sufficient for over $2 \mathrm{kV}$ operations.

The winding structure of the $1 \mathrm{MJ}$ coil is almost identical to the $100 \mathrm{~kJ}$ coil. The coil, 183 turns $\times 14$ layers, was wound on the GFRP bobbin and DFRP spacers and Litz wires were inserted in each layer as shown in Fig. 6. The $1 \mathrm{MJ}$ coil was designed with the same stability criteria as that of the $100 \mathrm{~kJ}$ coil assuming an adiabatic condition. The maximum AC loss density in the coil during the rated discharge of $1 \mathrm{~s}$ is $4.64 \mathrm{~kJ} / \mathrm{m}^{3}$. The AC loss can be absorbed by the coil which possesses high thermal diffusivity. The operational margin of the coil is much higher than the adiabatic operating condition, which was verified during the $100 \mathrm{~kJ}$ coil tests.
TABLE II

SPECIFICATIONS OF THE LTS PULSE COIL

\begin{tabular}{lll}
\hline \hline Specification & $\begin{array}{l}100 \mathrm{~kJ} \\
\text { Prototype coil }\end{array}$ & $\begin{array}{l}1 \mathrm{MJ} \\
\text { Full size coil }\end{array}$ \\
\hline Dimension of the coil windings & & \\
$\quad$ Inner diameter: 2a1 & $0.305 \mathrm{~m}$ & $0.600 \mathrm{~m}$ \\
Outer diameter: 2a2 & $0.509 \mathrm{~m}$ & $0.804 \mathrm{~m}$ \\
Length: 2L & $0.402 \mathrm{~m}$ & $1.098 \mathrm{~m}$ \\
Total turn number & $67 \times 14$ layers $=$ & $183 \times 14$ layers \\
& 938 turns & $=2562$ turns \\
Coil inductance & $0.20 \mathrm{H}$ & $2.00 \mathrm{H}$ \\
Maximum magnetic field & $2.2 \mathrm{~T}$ & $2.48 \mathrm{~T}$ \\
Magnetic stored energy & $100 \mathrm{~kJ}$ & $1 \mathrm{MJ}$ \\
Start operating current & $1000 \mathrm{~A}$ & $1000 \mathrm{~A}$ \\
Stop current after 1 sec discharge & $707 \mathrm{~A}$ & $707 \mathrm{~A}$ \\
Maximum coil voltage & $70.7 \mathrm{~V}$ & $707 \mathrm{~V}$ \\
Maximum AC loss density in the coil & $3.52 \mathrm{~kJ} / \mathrm{m}^{3}$ & $4.64 \mathrm{~kJ} / \mathrm{m}^{3}$ \\
Total AC loss of the coil & $32 \mathrm{~J}$ & $212 \mathrm{~J}$ \\
Discharge energy per a coil & $50 \mathrm{~kJ}$ & $500 \mathrm{~kJ}$ \\
Total length of conductor & $1,200 \mathrm{~m}$ & $6,410 \mathrm{~m}$ \\
Number of DFRP spacer & 720 & 1,200 \\
Total cross-section of Litz wire & $4,774 \mathrm{~mm}$ & $6,120 \mathrm{~mm}$ \\
Coil weight & $400 \mathrm{~kg}$ & $1,100 \mathrm{~kg}$ \\
\hline \hline
\end{tabular}

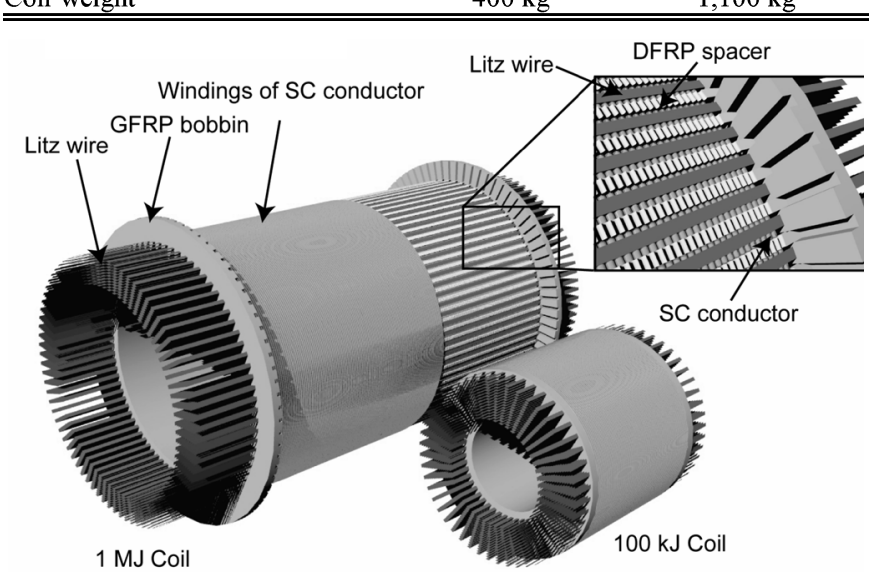

Fig. 6. Winding structure of the 1 MJ LTS pulse coil with the $100 \mathrm{~kJ}$ coil.

We have fabricated the $1 \mathrm{MJ}$ full size coil with the same design standard as that of the $100 \mathrm{~kJ}$ coil, to confirm whether the large stability margin expected from the result of $100 \mathrm{~kJ}$ coil can be achieved. Moreover, we are planning to verify the application limit of this design concept by doing the overcurrent excitation tests and the electrical discharge tests more than the rated value.

\section{B. Fabrication of 1 MJ Coil}

The winding process of the $1 \mathrm{MJ}$ coil was conducted at the factory of Shibuya Kogyo Co., Ltd. The special winding machine, which has been developed in NIFS to wind the $100 \mathrm{~kJ}$ prototype coil, was improved to control the twisting angle of the conductor more precisely by increasing the number of angle sensors and modifying the control software.

During the winding process, it was very important to inspect defects of the polyimide insulation tape wrapped on the conductor because the total length of the conductor became $6.4 \mathrm{~km}$ for the $1 \mathrm{MJ}$ coil. The inspection has been executed using a CCD camera and red LED bars as shown in Fig. 7 with a sample of the defect. These winding processes have been implemented semi-automatically in order to aim the mass production of the coil in the next step. Fig. 8 shows the coil after the completion of the windings. Fig. 9 shows the coil after vacuum-impregnation with epoxy resin. This $1 \mathrm{MJ}$ full size coil is being installed in a 

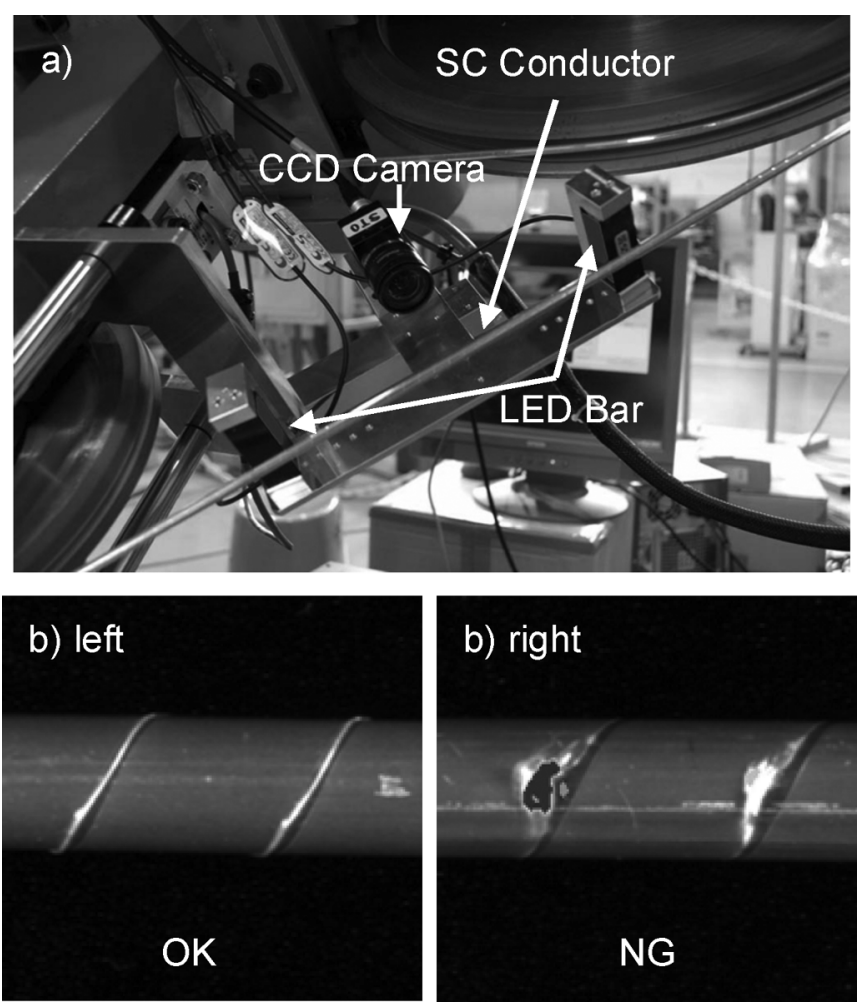

Fig. 7. (a) Inspection units of the insulator of the SC conductor with the CCD camera and the LED bar. (b) Evaluation by image data processing; OK (left), NG (right).

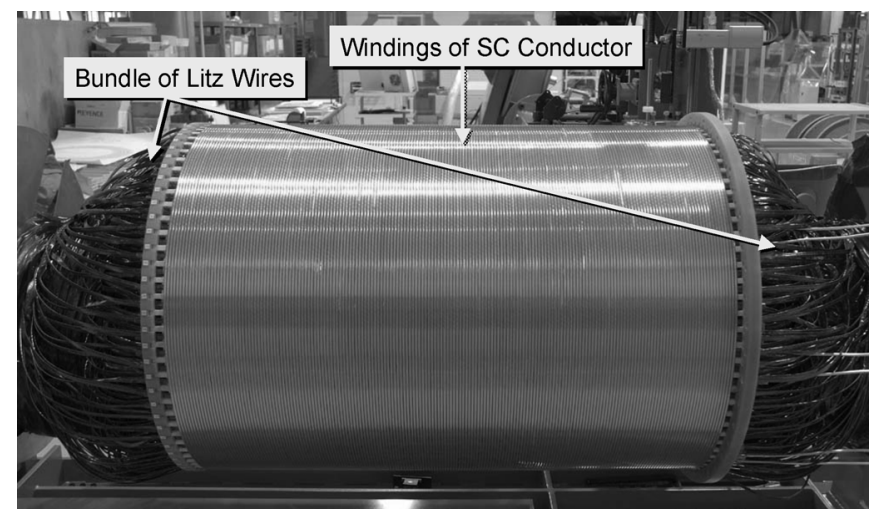

Fig. 8. $1 \mathrm{MJ}$ coil after the completion of 14 layers windings.

single coil test cryostat as shown in Fig. 10. The total cooling capacities of three GM cryocoolers are 4.5 W @ 4 K and $180 \mathrm{~W}$ @ $50 \mathrm{~K}$, which are sufficient for the main steady heat loads from 1 kA HTS current leads (1.0 W @ 4 K and 84 W @ 50 K).

\section{Summary AND Future Plan}

We have successfully developed the conduction-cooled LTS pulse coils as a key technology for the UPS-SMES. The high performance of the conduction-cooled coil has been demonstrated by the cooling and excitation tests of the $100 \mathrm{~kJ}$ prototype coil and its applicability was also confirmed by the energy extraction tests as the UPS-SMES with power converters. The $1 \mathrm{MJ}$ coil has been successfully constructed with the same design concept as that of the $100 \mathrm{~kJ}$ coil.

After the evaluation of the stability margin of the $1 \mathrm{MJ}$ full size coil, the $1 \mathrm{MJ}$ coil size is planned to be revised in order to

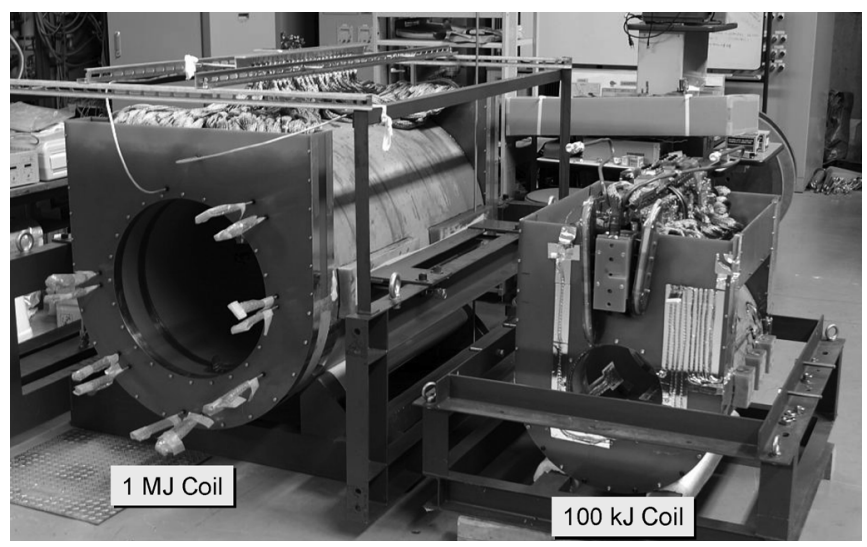

Fig. 9. $1 \mathrm{MJ}$ coil covered with GFRP and impregnated with epoxy resin with the comparison of the $100 \mathrm{~kJ}$ coil.

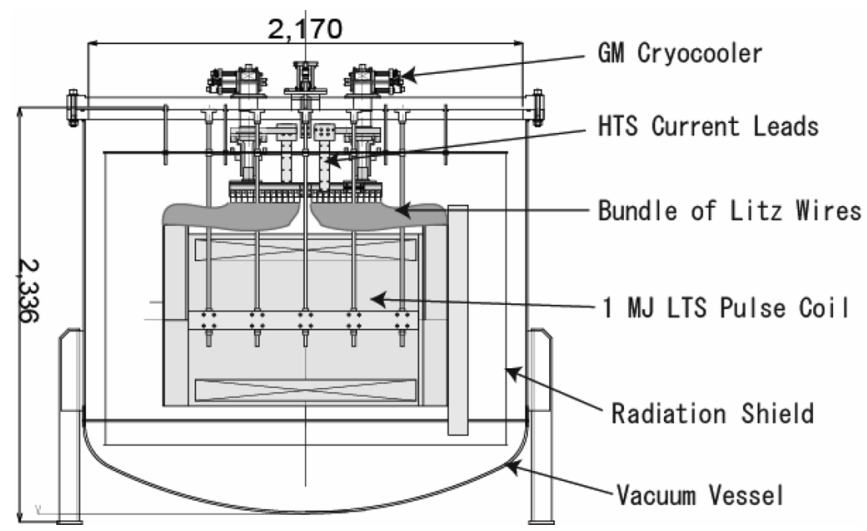

Fig. 10. Test cryostat for the 1 MJ LTS pulse coil.

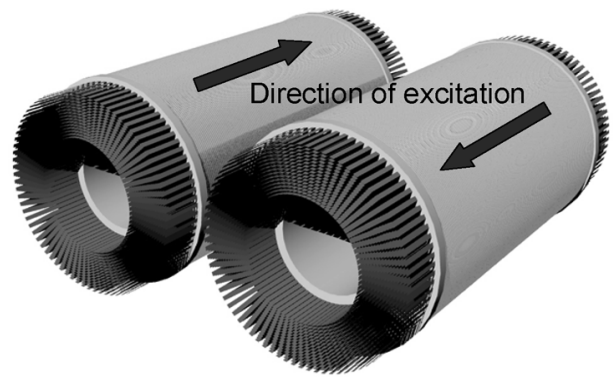

Fig. 11. A pair of coils arrangement for a $1 \mathrm{MW}, 1 \mathrm{~s}$ UPS-SMES.

minimize a cost of a UPS-SMES production. A pair of downsized and cost reduction $1 \mathrm{MJ}$ coils excited in the opposite direction as shown in Fig. 11, is built into the cryostat as a $1 \mathrm{MW}, 1 \mathrm{~s}$ UPS-SMES. We are planning to develop a commercial $1 \mathrm{MW}$, 1s UPS-SMES in a few years.

\section{REFERENCES}

[1] L. Ottonello et al., "The largest Italian SMES," IEEE Trans. Appl. Supercond, vol. 16, no. 2, pp. 602-607, 2006.

[2] S. Nagaya et al., "Field test results of the 5 MVA SMES system for bridging instantaneous voltage dips," IEEE Trans. Appl. Supercond, vol. 16, no. 2, pp. 632-635, 2006.

[3] T. Mito et al., "Validation of the high performance conduction-cooled prototype LTS pulse coil for UPS-SMES," IEEE Trans. Appl. Supercond, vol. 16, no. 2, pp. 608-611, 2006.

[4] A. Kawagoe et al., "Heat transfer properties of a conduction-cooled prototype LTS pulse coils for UPS-SMES," IEEE Trans. Appl. Supercond, vol. 16, no. 2, pp. 624-627, 2006.

[5] M. Steurer et al., "Frequency response characteristics of a $100 \mathrm{MJ}$ SMES coil-Measurements and model refinement," IEEE Trans. Appl. Supercond., vol. 15, no. 2, pp. 1887-1890, 2005. 